\title{
The Coherence Dilemma in
}

\section{Peacebuilding and Post-Conflict Reconstruction Systems}

\section{Cedric de Coning ${ }^{*}$}

\section{Abstract}

This article analyses the coherence and coordination dilemma in peacebuilding and post-conflict reconstruction systems, with special reference to the United Nations' integrated approach concept. It argues that all peacebuilding agents are interdependent in that they cannot individually achieve the goal of the overall peacebuilding system. Pursuing coherence helps to manage the interdependencies that bind the peacebuilding system together, and coordination is the means through which individual peacebuilding agents can ensure that they are coherent with the overall strategic framework. The article is focused on two areas where the lack of coherence provides the most promise for improving peacebuilding coherence. The first is the need to generate a clearly articulated overall

* Cedric de Coning is a joint Research Fellow at NUPI (the Norwegian Institute of International Affairs) and ACCORD (the African Centre for the Constructive Resolution of Disputes). 


\section{Cedric de Coning}

peacebuilding strategy. The second is the need to operationalise the principle of local ownership. The article argues that without meaningfully addressing these shortcomings peacebuilding and post-conflict reconstruction systems will continue to suffer from poor rates of sustainability.

\section{Introduction}

It is estimated that approximately a quarter of all peace agreements fail in the first five-years after they have been signed (Collier 2003). ${ }^{1}$ There are many reasons why some peace processes are not sustainable. ${ }^{2}$ Some relate to the role of spoilers (Stedman 1997; Newman \& Richmond 2006; Gueli, Liebenberg \& Van Huyssteen 2005:11) and the dynamics of post-conflict settlements (Du Toit 2003:105; Du Toit 2001) whilst others are associated with shortcomings in the support provided by the international community (Stedman, Cousens \& Rothchild 2002; Chesterman 2004; Fukuyama 2004; Paris 2004). This paper is focused on one of the aspects that contributes to the lack of sustainability in the latter context, namely the coherence dilemma that continues to cause stress to international peacebuilding systems.

Despite a growing awareness that the security, development, political, human rights, humanitarian and rule of law dimensions of peacebuilding systems are interlinked, the agencies ${ }^{3}$ that implement programmes in these dimensions are finding it extremely difficult to meaningfully integrate them. The goal of this paper is to analyse the coherence and coordination dilemma in peacebuilding and post-conflict reconstruction systems, with

1 The approximately 50\% figure sited generally has been demonstrated by Suhrke and Samset (2007) to be a misrepresentation, with a more correct finding of Collier (2003) being approximately $23 \%$.

2 For a quantitative analysis of the factors that have influenced the outcome of peacebuilding operations since 1944, see Doyle \& Sambanis 2000.

3 In this paper 'agents', and 'agencies' in the plural, are used as a collective term for all peacebuilding actors, i.e. those that execute programmes or otherwise undertake activities with the intent to engage in peacebuilding action, as defined in this paper. This includes international military forces, peace operations, development and humanitarian non-governmental organisations (NGOs) and UN agencies, departments, funds and programmes, operational donor agencies, and states engaged in bilateral peacebuilding actions. 
the objective of generating meaningful findings and recommendations with regard to (a) improving coherence and coordination within and across state and civil agencies engaged in peacebuilding and post-conflict reconstruction systems, and (b) initiating, encouraging and supporting initiatives that will improve coherence and coordination in the international, including especially the United Nations (UN), African Union (AU) and Southern African Development Community (SADC) peacebuilding systems.

The paper is presented in two parts. The first defines and analyses peacebuilding and post-conflict reconstruction in the context of the coherence and coordination deficit. The second identifies two key priority areas where improved coherence and coordination are likely to have the most meaningful impact.

\section{Peacebuilding and Post-Conflict Reconstruction}

In the post-Cold War era, the focus of international conflict management has increasingly shifted from peacekeeping, which was about maintaining the status quo, to peacebuilding, which has to do with managing change (Eide 2004). The nexus between development, peace and security has become the central focus of the international conflict management debate (Uvin 2002:5), and peacebuilding is increasingly seen as the collective framework under which these peace, security, humanitarian, rule of law, human rights and development dimensions can be brought together under one common strategy at country level. ${ }^{4}$ These developments culminated, as the centrepiece of the UN reform proposals of the 2005 World Summit, in the establishment of the UN Peacebuilding Commission. In Africa, the New Partnership for Africa's Development (NEPAD) adopted a Post-Conflict Reconstruction Framework in 2005 and the AU adopted a Post-Conflict Reconstruction and Development Policy in 2006.

4 See, for instance, Secretary-General of the United Nations 2005 (In Larger Freedom...) and Secretary-General's High-Level Panel on System-wide Coherence 2006 (Delivering as One). 
For the purposes of this paper a complex peacebuilding or post-conflict reconstruction system is defined as a post-conflict ${ }^{5}$ intervention $^{6}$ that provides for parallel, concurrent and interlinked short-, medium- and longterm activities ${ }^{7}$ that work to prevent disputes from escalating, or avoid a relapse into violent conflict by addressing both the immediate consequences and the root causes of a conflict system. The peacebuilding or post-conflict intervention starts when a cease-fire agreement or peace agreement, which calls upon the international community to support the peace process, is implemented. It typically progresses through three stages, namely a stabilisation phase, a transitional phase, and a consolidation phase. ${ }^{8}$ The peacebuilding intervention ends when the host society has developed the capacity to manage and sustain its own peace process without external support.

A complex peacebuilding or post-conflict reconstruction system requires a wide range of internal ${ }^{9}$ and external ${ }^{10}$ actors, including governments, civil society, the private sector and international agencies, to work together in a coherent and coordinated effort. These peacebuilding or post-conflict

5 The UN distinguishes between preventative peacebuilding and post-conflict peacebuilding. This paper is focused on post-conflict peacebuilding.

6 Intervention in this context is not meant to imply the use of force, but is rather used in the broad sense of taking action aimed at bringing about change.

7 'Activities' are used throughout this article as an umbrella term for policies, programmes and projects and all other related actions taken by peacebuilding agents to pursue their respective objectives. It is defined by the Organization for Economic Cooperation and Development (OECD) as action taken or work performed through which inputs, such as funds, technical assistance and other types of resources are mobilised to produce specific outputs. See OECD 2002.

8 There are a number of different interpretations of these phases, but most convey the same essential progression. See, for instance, AUSA \& CSIS 2002, in which three stages are identified, namely: the initial response, transformation and fostering sustainability. For a more detailed explanation of the three stages referred to here, namely stabilisation, transitional and consolidation, see De Coning 2007.

9 Internal actors are all local actors in the country or conflict system where peacebuilding activities take place.

10 External actors are all international actors engaged in undertaking peacebuilding activities in a given country or conflict system. 
reconstruction agents undertake a broad range of activities that span the security, political, development, human rights, humanitarian and rule of law dimensions. ${ }^{11}$ Collectively and cumulatively, these activities address both the causes and consequences of the conflict system, and builds momentum over time that facilitates the transformation of the system and increases its resilience to deal with potential outbreaks of violent conflict and its ability to sustain peace. In the short term the goal of peacebuilding or post-conflict reconstruction interventions is to assist the internal actors with consolidating the peace process and preventing a relapse into conflict, but its ultimate aim is to support them in transforming the causes of the conflict and laying the foundations for social justice and sustainable peace and development. ${ }^{12}$

\section{Coherence and Coordination}

The need for, and benefits of, improved coherence are widely accepted today in the international multilateral governance context. There is now broad consensus that inconsistent policies and fragmented programmes entail a higher risk of duplication, inefficient spending, a lower quality of service,

11 There is broad consensus on these dimensions. See, for instance, the African Union's Post-Conflict Reconstruction and Development Framework (African Union 2006) that comprises six constitutive elements, including gender as a self-standing element. The UN Secretary-General's Note on Integrated Missions (2006) lists seven dimensions, namely: political, development, humanitarian, human rights, rule of law, social and security. Note that humanitarian assistance is included as one of the peacebuilding dimensions in the UN Integrated Mission concept. The Utstein Report (Smith 2003) and NEPAD's Post-Conflict Reconstruction Policy Framework for Africa (NEPAD 2005) include humanitarian assistance as part of the socio-economic development category. Many in the humanitarian community argue that humanitarian assistance falls outside the scope of peacebuilding, and should not be included in any such peacebuilding categorisation. See, for instance, Weir (2006). The humanitarian dimension is included as one of the peacebuilding dimensions throughout this paper as per the UN concept, with due regard for the principle of the independence of humanitarian action, as recognised in paragraph 10 of the SecretaryGeneral's Note on Integrated Missions.

12 This definition was initially developed by the author and Senzo Ngubane in De Coning and Ngubane 2004, and was further elaborated by the author in De Coning 2005. For a thorough overview and discussion of peacebuilding definitions, see Barnett et al 2007:35-58. 
difficulty in meeting goals and, ultimately, a reduced capacity for delivery. ${ }^{13}$ There is, however, a considerable gap between the degree to which the benefits of coherence are held to be of self-evident and operational reality. The lack of coherence among field activities in the humanitarian relief, development, political and security spheres have been well documented in a number of evaluation reports and studies, ${ }^{14}$ and is acknowledged in a number of recent UN reports. ${ }^{15}$

For example, the Joint Utstein Study of peacebuilding, that analysed 336 peacebuilding projects implemented by Germany, the Netherlands, the United Kingdom and Norway in the 1990s, has identified a lack of coherence at the strategic level, what it terms a 'strategic deficit', as the most significant obstacle to sustainable peacebuilding (Smith 2003:16). The Utstein study found that more than $55 \%$ of the programmes it evaluated did not show any link to a larger country strategy. The evaluation studies cited have consistently found that the peacebuilding interventions undertaken to date have lacked coherence, and that this has undermined their sustainability and ability to achieve their strategic objectives.

It is possible to distinguish between four elements of coherence ${ }^{16}$ in the peacebuilding context, namely: (1) agency coherence, i.e. consistency ${ }^{17}$ among the policies and actions of an individual agency, including the

13 See Policy Coherence: Vital for Global Development 2003.

14 Amongst others: Dahrendorf 2003; Porter 2002; Sommers 2000; Stockton 2002; Donini 2002; Reindorp \& Wiles 2001 and Duffield et al 1998.

15 See footnotes 4 and 13 .

16 See Picciotto 2005:13-14, where he identifies (1) internal coherence, (2) whole of government coherence, (3) donor coherence and (4) country-level coherence.

17 Consistency in this context is not necessarily ethical, i.e. doing like under like circumstances with respect to any one rule or norm, i.e., avoiding double standards; instead it refers to one agency, government, or system not working at cross-purposes with itself in a more general sense. This does not imply that there is no room for differences and debate during the policy formulation and review process, but once a policy or intervention has been agreed on it needs to be implemented in such a way that all the different elements of the agency, government or system contribute to the overall objective in a complementary fashion. I am grateful to Ramesh Thakur (The Centre for International Governance Innovation) for pointing out this difference (e-mail correspondence, 15 May 2007). 
internal consistency of a specific policy or programme; (2) whole-ofgovernment coherence, i.e. consistency among the policies and actions of the different government agencies of a country; ${ }^{18}$ (3) external coherence, i.e. consistency among the policies pursued by the various external actors in a given country context (harmonisation ${ }^{19}$ ); and (4) internal/external coherence, i.e. consistency between the policies of the internal and external actors in a given country context (alignment ${ }^{20}$ ). The degree to which a specific peacebuilding system can be assessed to be more, or less, coherent will be a factor of all four elements of coherence.

In this paper 'coherence' is understood as the effort to direct the wide range of activities undertaken in the political, development, human rights, humanitarian, rule of law and security dimensions of a peacebuilding system towards common strategic objectives. ${ }^{21}$ It is important to recognise, however, that the dynamic and non-linear nature of complex systems means that coherence can never be fully attained (Cilliers 2002). It is possible, however, to distinguish between systems where there is less, or more, coherence, and coherence is thus about degree during a process, not about an end-state. Coherence also needs to be understood in the context of the natural tensions, and therefore trade-offs, between the four elements of coherence. In the real world, peacebuilding agents, more often than not,

18 Note for instance the Canadian approach aimed at combining Diplomacy, Defence \& Development, the so-called '3D' approach.

19 Note the 'Rome Declaration on Harmonization' of 25 February 2003. See <www.aidharmonization.org>, accessed on 12 May 2007.

20 Note in this context the 'Paris Declaration on Aid Effectiveness' of 2 March 2005. See $<$ www.oecd.org >, accessed on 12 May 2007.

21 For alternative definitions, see, for instance, Policy Coherence: Vital for Global Development (2003) that defines policy coherence as '.. the systematic promotion of mutually reinforcing policy actions across government departments and agencies creating synergies towards achieving the agreed objectives'. 
have to settle for 'second best' or 'partially coherent' solutions in order to establish a workable foundation for cooperation. ${ }^{22}$

A number of potentially negative effects of pursuing coherence has been identified. First, in some cases short-term political and security considerations may override longer-term development considerations and this may undermine the very socio-economic rehabilitation on which sustainable peacebuilding depends. Second, undue pressure on internal actors may materialise when external actors form a coherent block on certain issues. Third, the neutrality, impartiality and independence of humanitarian action may be negatively affected when integrated with political and security activities. ${ }^{23}$ Whilst these three examples can be said to be examples of poor coherence trade-offs, rather than inherently negative effects of pursuing coherence per se, the more important point is that pursuing coherence can generate unintended consequences. When evaluating the impact of coherence, one should consider with care the balance that has been struck among the four elements of coherence, the transaction cost in terms of the time and resources invested in coordination, as well as any unintended consequences that may have come about in the process (Aoi et al 2007).

If 'coherence' is the aim, then 'coordination' is the activity through which coherence is pursued. Whilst coordination seems to be the most obvious and logical of pursuits, especially in the highly dynamic and fragmented complex emergency context, empirical evidence suggests that it is, in reality, a highly

22 I am grateful to Robert Picciotto (King's College) for adding the notion of trade-offs between the four coherence vectors. He argues that it is important to stress that coherence only leads to unintended and poor results if the trade-offs among its four dimensions are badly struck. When this is acknowledged, alternative coherence solutions become possible, and this may allow for gradual repositioning of imperfect or partial coherence. For instance, the capacity building of local actors may allow gradual upgrading of domestic institutions so that they exercise their voice option with greater vigour and improve the alignment of internal and external goals (e-mail correspondence, 14 May 2007).

23 See CDA (Committee for Development Assistance) Collaborative Learning Project 2006:24. This report was prepared for the OECD/DAC Network on Development Evaluation and the Network on Conflict, Peace and Development Cooperation (CPDC), as part of an ongoing initiative to develop the 'OECD/DAC Draft Guidance for the Evaluation of Conflict Prevention and Peacebuilding Activities'. 
controversial and dysfunctional activity. Barnes reports, in the context of her experiences in Mozambique, that the meaning of coordination often varied depending on which of the stakeholders employed it at a given moment, and that the various stakeholders competed to place their agencies at the forefront of the process to enhance their own legitimacy and subsequent fundraising capacities (Barnes 1998). Uvin provides a useful list of reasons why effective coordination appears to be so elusive: 'The lack of co-ordination is partly due to widely recognized factors: the multitude of actors, often numbering in the hundreds; the high cost in time and money that effective co-ordination entails; the need for donors to satisfy their own constituencies and serve their national interests; competition for influence and visibility between donors; and the general unwillingness of actors to limit their margin for maneuver by the discipline of coordination' (Uvin 1999:29). Donini (2002) argues that the effective provision of assistance requires that duplication, waste and competition among agencies be avoided, but he cautions that the objectives and organisational cultures of the development, humanitarian and peacekeeping communities are essentially irreconcilable within a single centralised structure. Paris (2004) cautions that coordination can create a sense of 'false-coherence' where fundamental tensions and differences are glossed over for the sake of operational expediency, only to re-surface and undermine cooperation at the critical moments when cohesion is most needed.

From these and many other reports it is clear that coordination is not a 'good' in and of itself. There is a limit to the added value of coordination. The time and resources devoted to coordination necessarily increase the administrative costs of delivering assistance. ${ }^{24}$ There is a point at which the cost benefit ratio will become negative, and coordination activities should thus be proportional to the overall effort. At the same time, it is clear that no one is advocating that there should be no coordination. In fact, to the contrary, and as Peter Uvin (1999:18) points out: 'all documents on peacebuilding stress the need for improved co-ordination: there is no single

24 See Stockton (2002) and the argument he makes that coordination is in effect a levy on the scarce resources allocated to beneficiaries. 


\section{Cedric de Coning}

need more emphasized'. There seems to be a tension between the need for improved coordination on the one hand, and the potential limiting effects coordination may have on the ability of individual agents to exercise control over their own programming and allocation of resources.

Coordination can entail developing strategies, determining objectives, planning, sharing information, dividing roles and responsibilities, and mobilising resources (Minear \& Chellia 1992:3). It should be recognised, however, that not all the agents in the system need to be engaged in all coordination activities. And those that are, do not need to be engaged at the same level of intensity. There will typically be a core network that is well connected, an intermediate group that is regularly connected, and a periphery that is infrequently connected, if at all. The development of an overall strategic framework would, for instance, usually take place among a relatively limited network at the outset, but it could then be refined through various participatory and consultative processes that could inform and shape the overall direction of the system, and serve to build a wider base of ownership and accountability. Whilst there should be coordination between the humanitarian and the peace and security dimensions of a peacebuilding system, the level and intensity of this link do not have to be of the same quality as that of the link between the other dimensions of the system. It is thus possible to accommodate a range of appropriate levels of coordination within one larger system.

Thus, whilst coherence and coordination are interlinked, one should not assume a linear or causal relationship, as the one does not necessarily lead to the other. Each needs to be independently considered in order to achieve a comprehensive understanding of the inter-linkages between the two.

\section{The Logic of Coherence}

A peacebuilding or post-conflict reconstruction system consists of a large number of independent agents that collectively carry out a broad range of activities across the dimensions of the system. These agents are independent in that they are each legally constituted in their own right, have their own 
organisational goals and objectives, have their own access to resources, and are in control of those resources, i.e. they have the power to make decisions about the allocation of those resources. Some of these agents are linked together in networks or sub-systems. The humanitarian community can be recognised as a distinct network within the larger peacebuilding system, in that they have broadly similar aims, operate on the same principles, and consciously try to work together in a networked pattern at country-level through the humanitarian coordinator system, cluster approach and joint resource mobilisation. Another example is the various members of the UN family that, at country-level, form a unique sub-system in that they have a common identity, they employ various mechanisms to pursue a common objective, and they actively strive to be seen to be acting as one System, with the slogan 'delivering as one'. 25 However, each UN agency within the UN system, even when it is organised at country-level into a 'UN System', remains a separate and independent agency with the ability to control its own resources.

A distinguishing feature of a peacebuilding or post-conflict reconstruction system, however, is that all the agents and their activities are interdependent, in that no single agency, network or sub-system can achieve the ultimate goal of the peacebuilding system - addressing the root causes of the conflict and laying the foundation for social justice and sustainable peace - on its own. Each agency independently undertakes activities that address specific facets of the conflict spectrum, but a collective (combined) and cumulative (sustained over time) effect is needed to achieve the overall peacebuilding goal. The peacebuilding or post-conflict reconstruction system thus consists of all of the agents that are necessary to achieve the overall peacebuilding goal, and the system effect is brought about by their interdependence.

25 'Delivering as One' was the title of the Report of the High-level Panel on UN System-wide Coherence, and has subsequently become shorthand for pursuing coherence within the UN Country Team system. During 2007, eight countries would pilot different models to deliver as 'One', looking at common elements, such as 'One Programme', 'One Budgetary Framework', 'One Leader' and 'One Office'. See <www.undg.org $>$ for more details. 


\section{Cedric de Coning}

Each agent is only contributing a part of the whole, and it is the overall collective and cumulative affect that builds momentum towards sustainable peace and development. If the peace process fails and the conflict resumes, the time and resources invested have been wasted. It is only if the combined and sustained effort proves successful in the long-term that the investment made can be said to have been worthwhile. The success of each individual activity is linked to the success of the total collective and cumulative effect of the overall undertaking (Smuts [1926] 1987:78). It is thus in the best interest (rational choice) of each individual peacebuilding agent to ensure that the activities it undertakes are coherent with the overall peacebuilding strategy, because doing so will greatly increase the likelihood that the overall peacebuilding goal will be achieved, and thus, that the individual activity would be successful.

When the need for coherence between each individual activity, the agents that undertake them, and the overarching peacebuilding goal is established, coordination emerges as the tool with which to pursue this logic. In this context, coordination is the process that ensures that an individual peacebuilding agent is connected to the larger peacebuilding system of which it is a part.

\section{Pursuing Coherence}

In order to pursue coherence in a given peacebuilding or post-conflict reconstruction system, agents would have to pursue all four elements of coherence, using all the tools of coordination (developing strategies, determining objectives, planning, sharing information, dividing of roles and responsibilities, and mobilising resources). It is not possible to address all these vectors in this paper. Instead, this paper will focus-in on two areas where the lack of coherence has had the most damaging effect on achieving sustainability, and which; correspondingly, hold the most promise for improving peacebuilding coherence, once addressed.

The first is the need to generate a clearly articulated overall peacebuilding strategy that can provide the various peacebuilding agents with a common 
frame of reference which it can use as a benchmark for coherence, i.e. the framework with which it should be coherent. It is impossible to achieve coherence if the framework, with which individual agents have to be coherent, has not been developed and shared with all the agents in the system.

The second is the need to operationalise the principle of local ownership. The inability of the external actors to give meaning to their stated policies and principles of alignment is one of the most significant shortcomings in the context of peacebuilding coherence. It is also one of the most challenging, with few obvious solutions and extensive entrenched practices and established relationships. It would thus require considerable political will and focused attention to adjust, but the paper argues that without meaningfully addressing this shortcoming peacebuilding and post-conflict reconstruction systems will continue to suffer from poor rates of sustainability and success. It is inconceivable that a peacebuilding system can achieve sustainability if either of these two aspects - an overarching peacebuilding strategy or local ownership - are lacking.

\section{The Need for a Clearly Articulated Overall Peacebuilding Strategy}

The importance of an overall strategic process is widely recognised and accepted but poorly applied in practice (Paris 2004). As the Utstein and other recent studies cited ${ }^{26}$ have pointed out, however, the lack of a clearly articulated overall strategy is, in fact, a critical shortcoming in most past and contemporary peacebuilding systems. The first prerequisite for coherence in any peacebuilding or post-conflict reconstruction system is the development of an overall strategic framework. Without it the various peacebuilding agents have no benchmark against which they can judge the degree to which they are coherent with the overall peacebuilding strategy.

A strategic framework should reflect a common understanding of the problem, i.e. the root causes of the conflict and the more immediate triggers

26 See footnote 11. 


\section{Cedric de Coning}

that have caused the outbreak of violent conflict, and that may be continuing to stress the peace process. It should be grounded in a shared long-term vision of the future path the country or conflict system wishes to realise, and it should contain a clearly articulated multi-dimensional and integrated strategy for the short to medium future direction of the peace process.

A strategic framework is not an operational and tactical implementation plan. Implementation planning is best done by those agents that have the responsibility for allocating their resources, and although such plans should be coordinated with partners, shared within sector and cluster coordination processes, and aligned with overall strategy, it would be impossibly complex to design one overall system-wide operational and tactical implementation plan. In fact, attempts aimed at controlling operational and tactical implementation planning at some central point are likely to cause dysfunction as a result of the simplification that any such central planning process would have to impose. It is thus important to distinguish between a strategic framework on the one hand, that identifies common goals and objectives, milestones and benchmarks, and the broad processes through which they should be pursued, coordinated and integrated, and operational and tactical implementation planning on the other.

For an overall peacebuilding strategy to be a meaningful vehicle for systemwide coherence, it needs to be transparent, readily available to all agencies, open for input and consultation, and regularly revised and updated. It is also critical that the overall effect of the strategy needs to be closely monitored. If every peacebuilding agency has access to the strategic framework, and information related to the effect it is having on the peace process, they would be able to use this information to inform and adjust their own strategic processes and implementation planning.

Unfortunately, we have very few examples of successfully applied strategic frameworks to date (Patrick \& Brown 2007:130). This is the most critical shortcoming in international peacebuilding systems. What we do have at this stage are various partial processes. For instance, there is the UN Development Assistance Framework (UNDAF) that is a vehicle for aligning the strategies 
of the various UN development agencies and the host government for a specific period at country level. The humanitarian community has developed the humanitarian Consolidated Appeal Process (CAP), but this is more of a resource mobilisation tool than a strategic planning tool. In the context of the UN integrated missions model the UN has developed the Integrated Missions Planning Process (IMPP). It is still being refined and piloted, but it is primarily a UN System planning tool and its link with the need for an overall strategic framework that goes beyond the UN family is still unclear. It could become the catalyst for such a larger strategic process, but there is also a danger that it may generate such internal momentum, and become so wrapped-up in its internal planning processes, benchmarking and reporting, that is neglects the need to connect the UN planning process with the wider peacebuilding strategic framework.

The most broad and pervasive process to date is probably the Poverty Reduction Strategy (PRS) process, facilitated by the World Bank and aimed at aligning the overall development strategy of the external actors and the host Government. The PRS process was, however, developed in the development context and thus tends to focus on macroeconomic and financial issues. It is not designed specifically for managing post-conflict transitions in fragile states. There have been attempts to develop system-wide strategies that go beyond the development realm in a post-conflict setting, such as the Strategic Framework process in Afghanistan and the Results Focused Transitional Framework (RFTF) in Liberia. However, in both these experiments the linkages with the UN peace operation, and thus the UN Security Council mandates, were weak. The lessons learned from these experiments are that for any overall peacebuilding strategy to be meaningful it needs to be firmly grounded in the political peace process that lies at the core of the international conflict management intervention, i.e. it should focus on those areas that secure and consolidate the peace (United Nations Security Council 2007:7). This does not mean that the developmental, humanitarian, human rights, and rule of law dimensions should be subsumed to the political and security dimensions, but rather that the overall effect of the integrated approach needs to facilitate and secure the peace process. It is the focus on the conflict 


\section{Cedric de Coning}

prevention aspect that gives peacebuilding and post-conflict reconstruction its unique identity, and the overall strategy during the peacebuilding phase needs to reflect this emphasis on consolidating the peace process.

The UN Peacebuilding Commission has been mandated to address this challenge, and it has, in its first year of existence, facilitated the development of integrated peacebuilding strategies for Burundi and Sierra Leone. According to the Commission's annual report the purpose of an integrated peacebuilding strategy is 'to ensure coherent, prioritized approaches that involve international donors and agencies' (Peacebuilding Commission 2007). It is still too early to judge these Peacebuilding Commission facilitated integrated peacebuilding strategies but whilst they look promising on the grounds that they are clearly focused on those areas that could threaten the consolidation of peace, they are also hamstrung by the UN's internal division of responsibilities that limit the focus of the Peacebuilding Commission to those post-conflict situations no longer under the UN Security Council spotlight. As a result, the Peacebuilding Commission's integrated peacebuilding strategies are designed around the demands of the consolidation phase of peacebuilding systems. It would appear as if a division of responsibilities has emerged where the stabilisation and transitional phases, in the UN system context, and as long as a UN peacekeeping operation is deployed, should be managed by the UN integrated approach concept, and from a planning perspective, the new Integrated Missions Planning Process (IMPP), whilst the consolidation phase, or that part of it that follows after the withdrawal of the UN peacekeeping operation, is the purview of the Commission's integrated peacebuilding strategy. This is a field experiencing rapid innovation. The Peacebuilding Commission's integrated peacebuilding strategies have been developed in 2007. The UN's integrated approach has been under development since 2000. The IMPP was developed in 2006 and 2007, and will be rolled out in 2008. The AU's Post-Conflict Reconstruction and Development policy was adopted in 2006. These new developments need time to be refined through practice before they can be meaningfully analysed. 
Without a clear country strategy, and without feedback on the progress made in achieving that strategy, individual agents are unable to position, adjust and monitor the degree to which they may be making a contribution to the achievement of the overall peacebuilding goal. The process of developing and adjusting a common country strategic framework, and continuously sharing this information with all the agents in the system, thus acquires a critical role in the complex peacebuilding systems approach. The degree to which such a strategic planning system is currently absent goes a long way to explaining the lack of coherence evident in past and present peacebuilding and post-conflict reconstruction systems.

\section{The Need to Ensure the Primacy of Internal Actors in the Peacebuilding System}

There is wide recognition that externally driven post-conflict peacebuilding processes are unsustainable (Peacebuilding Forum Conference 2004:2). Peacebuilding and post-conflict reconstruction activities need to be needbased, and the priorities, sequencing and pace of delivery need to be informed by the dynamics of the conflict system, through local ownership and meaningful internal/external coordination. It is also widely understood that peacebuilding activities that are not grounded in the socio-cultural belief systems that shape the worldview of the internal actors cause dysfunction. Achieving a balanced and meaningful partnership between internal and external peacebuilding agents is thus one of the most important success factors for any post-conflict peacebuilding system. It is also one of the most difficult to achieve.

The principle that peacebuilding systems should be locally owned and led is well established in the policy realm. For instance, the Rome Declaration on Harmonization (2003) has generated the following four principles of harmonisation: (1) recipient countries coordinate development assistance, (2) donors align their aid with recipient countries' priorities and systems, (3) donors streamline aid delivery and (4) donors adopt policies, procedures and incentives that foster harmonisation. The Rome Declaration and 


\section{Cedric de Coning}

related policies are aimed at addressing the core structural inequality of the international assistance regime, namely that the external agency is empowered by virtue of being the benefactor. If left unchecked, external agencies tend to dominate the internal/external relationship. The most effective counterweight to this structural imbalance is the recognition that peace processes can only be sustainable when owned and led by internal actors. In this context, donors have come to accept the moral principle, and operational reality, that assistance has to be needs based and locally owned.

However, this is easier said than done and external actors have reported that they have encountered a number of obstacles when trying to implement policies that encourage local ownership, especially in the fragile state and post-conflict contexts. External actors find it difficult to identify credible internal actors with whom they can enter into a meaningful partnership, especially in the stabilisation and transitional phases before elections are held. This is because the parties emerging out of conflict typically represent ambiguous constituencies, and there are often conflicting claims of ownership and support. The internal actors also typically lack the time, resources, technical expertise and support systems to engage meaningfully with the external actors. In fact, the concept of fragile states was initially developed in the donor context to refer to countries where the Government is unable or unwilling to establish a meaningful relationship with bilateral and multilateral donors.

The internal peacebuilding agents report that they typically feel intimidated by the momentum, scope and depth of the external intervention. They are overwhelmed by the pressure to engage with all the assessments, proposals and plans generated by the sudden influx of external actors, and they are frustrated that despite all this activity there is typically little to show, in terms of immediate delivery, for their time and effort. Whilst this is especially the case in the stabilisation and transitional phases, before or whilst the necessary capacities have been developed, it remains a problem long thereafter. The work of the Peacebuilding Commission in Burundi is a case in point. The development of the integrated peacebuilding strategy for Burundi put considerable additional strain on the Government of Burundi, and in June 
2007 the UN Country Team had to ask the Peacebuilding Commission not to further burden the Government of Burundi, and as a result the Commission decided to postpone the work on monitoring mechanisms (Peacebuilding Commission 2007:6).

External actors also point to the dysfunction caused by their own institutional cultures that emphasise output rather than impact. The pressure to rapidly respond, achieve planned outputs and to disburse funds within fixed timeframes (donor budget cycles) often result in external actors compromising on the time and resources needed to invest in identifying credible internal counterparts, generate consultative processes and develop meaningful local ownership. Consultations undertaken under pressure, for instance during rapid needs assessments, often serve to legitimise pre-conceived perceptions rather than add value by generating independent and objective opinions and analysis, and thus fail to reflect the true needs and priorities of the internal actors. Under pressure from the internal/external power imbalance, internal actor representatives make the common mistake of telling the external actors what they think the external agents would like to hear, rather than sharing with them their own perceptions and opinions of what kind of support they think they need, and the priorities as they perceive them.

There are two areas within the internal/external tension that have the potential to transform the inherent tensions in the relationship. The first builds on the fact that external actors have already recognised the principle, both for moral and functional reasons, that the peace process needs to be locally owned and led, and the second gives meaning to the principle that the support generated by the external agencies needs to be needs-based rather than supply-driven.

The first is the need to establish a new basis for the internal/external relationship, namely a rights-based approach that recognises that the internal actors have the human right to determine their own future. Meaningful sustainability requires that the internal actors should not just own the problem, but also the solutions. This rights-based approach implies that there should be processes in place, controlled by the internal actors, 


\section{Cedric de Coning}

that generate the needs-based information needed to assess, design, plan, coordinate and implement assistance programmes. Where such processes are not in place, the external actors should invest in facilitating them. Whilst external partners can facilitate such processes, they need to be truly locally owned and have meaningful power. This will be particularly challenging in post-conflict environments and fragile states, and both internal and external agents will need to invest considerable resources to developing processes and mechanisms that can generate meaningful local ownership. Without it, however, any investments made in peacebuilding systems are unlikely to be sustainable.

Whilst the first emphasis is thus on generating the processes that will serve to realise the human rights of the internal actors to determine their own destiny, the second emphasis is on ensuring that the combined and cumulative effect of the assistance offered has a positive effect on the internal actors, and that it is delivered at a rate that can be absorbed. If the ultimate aim of the postconflict reconstruction system is sustainable peace and development, then the overall strategy, and the pace of its implementation, should reflect the optimal balance between delivery and absorption. The legacy of violent conflict typically results in the internal actors having a much lower capacity to absorb assistance than the external actors anticipate. Post-conflict peacebuilding activities are typically planned at the outset, as intense shortto medium-term interventions and the bulk of the money theoretically available for these activities are made available in the early phases of the transition. Although well intended, the result is that large amounts are spent on activities that the internal actors simply cannot absorb.

There is a need to synchronise the rate of delivery with the rate of absorption. In general, this translates into programming those elements of the assistance package that are not aimed at emergency relief and early recovery over a longer term, and directing more of the earlier assistance to building the capacities that would be required to absorb downstream assistance. Internal actors will be best placed to absorb assistance towards the end of the transitional period when some basic capacities have been restored or newly established, and in the consolidation phase, when a newly elected government 
is in place that have the constitutional legitimacy to determine national priorities. The short- to medium-term high-impact approach currently favoured is not conducive to sustainable post-conflict peacebuilding and ultimately results in higher costs to both the internal and external actors.

\section{Conclusion}

This paper analysed the coherence and coordination dilemma in peacebuilding and post-conflict reconstruction systems. It was presented in two parts. The first defined and analysed peacebuilding and post-conflict reconstruction systems in the context of the coherence and coordination deficit. The second identified a few priority areas where improved coherence and coordination are likely to have the most meaningful impact.

It was pointed out that one of the reasons why coherence has proven elusive is because the agencies that undertake peacebuilding activities lack a shared understanding of the role of coherence and coordination in peacebuilding systems. It was suggested that there is a core logic for coherence in peacebuilding systems, namely that all peacebuilding agents are interdependent in that they can not individually achieve the goal of the overall peacebuilding system - addressing the root causes of the conflict and laying the foundation for social justice and sustainable peace and development. In this context, the role of coherence and coordination is to manage the interdependencies that bind the peacebuilding system together.

The paper focused on two areas where the lack of coherence has had the most damaging effect on achieving sustainability, and which, correspondingly, hold the most promise for improving peacebuilding coherence, once addressed. The first was the need to generate a clearly articulated overall peacebuilding strategy that can provide the various peacebuilding agents with a common frame of reference which they can use as a reference point for coherence, i.e. the framework with which it should be coherent. The paper argued that it is impossible to achieve coherence if the framework, with which individual agents have to be coherent, is missing. It also stressed the need to monitor, on an ongoing basis, the effect the overall 


\section{Cedric de Coning}

peacebuilding strategy is having on the host system, so that the strategy can be continuously adjusted to the dynamic environment, and so that the individual peacebuilding agents can independently make course directions to their own activities, and in so doing contribute to the synchronisation of the overall peacebuilding system.

The second was the need to operationalise the primacy of the principle of local ownership. The paper argued that the inability of the external actors to give meaning to their stated policies and principles of alignment is one of the most significant shortcomings in the context of peacebuilding coherence. It is also one of the most challenging, with few obvious solutions and extensive entrenched practices and established relationships. It would thus require considerable political will and focused attention to adjust, but the paper argues that without meaningfully addressing this shortcoming peacebuilding systems will continue to suffer from poor rates of sustainability and success.

The desire to improve the current poor record of sustainability and success in the field on peacebuilding is, however, an important and meaningful incentive, around which the international community in general, and African institutions such as the African Union in particular, can generate the necessary political will, both domestically and internationally. The stakes are high, especially for the 'bottom billion' born into the least developed and failed states periphery of the world system, but the potential rewards, for a more stable, secure and developed world system, are significant, and worth pursuing.

\section{Sources}

African Union 2006. Post-Conflict Reconstruction and Development Framework. Addis Ababa: African Union.

Aoi, Chiyuki; De Coning, Cedric \& Thakur, Ramesh (eds) 2007. The Unintended Consequences of Peacekeeping Operations. Tokyo: United Nations University Press.

AUSA (Association of the U.S. Army) \& CSIS (Centre for Strategic and International Studies) 2002. Post-Conflict Reconstruction: Task Framework. Washington D.C.: AUSA \& CSIS. 
Barnes, S. 1998. Humanitarian Aid Coordination during War and Peace in Mozambique. Uppsala: Nordiska Afrikainstitutet.

Barnett, Michael; Kim, Hunjoon; O’Donnell, Madalene \& Sitea, Laura 2007. Peacebuilding: What Is in a Name?' Global Governance 13 (1) Jan.-Mar. 2007, 35-58.

CDA (Commission of Development Assistance). 2006. Collaborative Learning Project. An Approach to DAC Guidance for Evaluating Conflict Prevention and Peacebuilding Activities. Cambridge, Massachusetts: CDA Collaborative Learning Project.

Chesterman, S. 2004. You, the People: The United Nations, Transitional Administration, and State-Building, Oxford: Oxford University Press.

Cilliers, P. 2002. Why We Cannot Know Complex Things Completely. Emergence 4 (1/2), 77-84.

Collier, P. et al 2003. Breaking the Conflict Trap: Civil War and Development Policy. Oxford/ New York: Oxford University Press/World Bank.

Dahrendorf, N. 2003. A Review of Peace Operations: A Case for Change. London: King's College.

De Coning, C.H. 2005. A Post-Conflict Reconstruction Policy Framework for Africa. A draft policy framework facilitated by ACCORD for NEPAD, May 2005. <www.nepad.org>

De Coning, C.H. 2007. Civil-Military Coordination and UN Peacebuilding Operations, in Langholtz, H., Kondoch, B. \& Wells, A. (eds), International Peacekeeping: The Yearbook of International Peace Operations, Volume 11, 2007. Brussels: Koninklijke Brill N.V.

De Coning, Cedric \& Ngubane, Senzo 2004. Peacebuilding in Southern Africa. An ACCORD report commissioned by JICA. <www.accord.org.za>

Donini, A. 2002. The Policies of Mercy: UN Coordination in Afghanistan, Mozambique and Rwanda, Occasional Paper \#22, Thomas J. Watson Jr. Institute for International Studies, Brown University, Providence.

Doyle, M.W. \& Sambanis, N. 2000. International Peacebuilding: A Theoretical and Quantitative Analysis. Washington D.C.: World Bank.

Duffield, M., Lautze S. \& Jones, B. 1998. Strategic Humanitarian Coordination in the Great Lakes Region 1996-1997. New York: United Nations Office for the Coordination of Humanitarian Affairs (OCHA).

Du Toit, Pierre. 2001. South Africa's Brittle Peace - The Problem of Post-Settlement Violence. New York: Palgrave.

Du Toit, Pierre. 2003. Why Post-Settlement Settlements? Journal of Democracy 14 (3).

Eide, Espen Barth. 2004. Presentation delivered at the 'DDR from a Peacebuilding Perspective' Course, 19-24 January 2004, Norwegian Defence International Center (NODEFIC).

Fukuyama, F. 2004. State-Building: Governance and World Order in the 21st Century. Ithaca: Cornell University Press. 


\section{Cedric de Coning}

Gueli, R., Liebenberg, S. \& Van Huyssteen, E. 2005. Developmental Peace Missions Theory. Pretoria: Council for Scientific and Industrial Research (CSIR).

Minear, L. \& Chellia, U. 1992. UN Coordination of the International Humanitarian Response to the Gulf Crisis. Providence: Thomas J. Watson Institute for International Studies.

NEPAD (New Partnership for Africa's Development) 2005. Post-Conflict Reconstruction Policy Framework for Africa.

Newman, Edward \& Richmond, Oliver (eds) 2006. Challenges to Peacebuilding: Managing Spoilers during Conflict Resolution. Tokyo: United Nations University Press.

OECD (Organization for Economic Cooperation and Development) 2002. Glossary of Key Terms in Evaluation and Results Based Management. Paris: OECD.

Paris, R. 2004. At War's End: Building Peace after Civil Conflict. Cambridge: Cambridge University Press.

Patrick, S. \& Brown, K. 2007. Greater than the Sum of its Parts: Assessing 'Whole of Government' Approaches to Fragile States. New York: International Peace Academy (IPA).

Peacebuilding Commission 2007. Annual Report of the Peacebuilding Commission S/2007/458A/62/137 of 25 July 2007.

Peacebuilding Forum Conference 2004. Building Effective Partnerships: Improving the Relationship between Internal and External Actors in Post-Conflict Countries, Peacebuilding Forum Conference, 7 October 2004, New York.

Porter, T. 2002. An External Review of the CAP. New York: United Nations Office for the Coordination of Humanitarian Affairs (OCHA).

Picciotto, Robert 2005. Fostering Development in a Global Economy: A Whole of Government Perspective, Introduction: Key Concepts, Central Issues. Paris: OECD.

OECD Observer. Available at <www.oecd.org > . Accessed on 10 May 2007.

Reindorp, N. \& Wiles, P. 2001. Humanitarian Coordination: Lessons from Recent Field Experience. A study commissioned by the Office for the Coordination of Humanitarian Affairs (OCHA), Overseas Development Institute (ODI), London.

Rome Declaration on Harmonization 2003. 25 February 2003. Available at <www.aidharmonization.org >. Accessed on 12 May 2007.

Secretary-General of the United Nations. 2005. In Larger Freedom: Towards Security, Development and Human Rights for All. Report of the Secretary-General of the United Nations. <www.un.org/largerfreedom>

Secretary-General of the United Nations. 2006. Revised Note of Guidance on Integrated Missions, dated 17 January 2006, and released under a Note from the Secretary-General on 9 February 2006, New York: United Nations.

Secretary-General of the United Nations. 2008. Decision Number 2008/24 - Integration, 25 June 2008 Policy Committee, New York: United Nations. 


\section{The Coherence Dilemma in Peacebuilding and Post-Conflict Reconstruction Systems}

Secretary-General's High-Level Panel on System-wide Coherence. 2006. Delivering as One. Report of the Secretary-General's High-Level Panel on System-wide Coherence, United Nations, New York. < www.un.org/events/panel>

Smith, D. 2003. Towards a Strategic Framework for Peacebuilding: the Synthesis Report of the Joint Utstein Study on Peacebuilding. Oslo: PRIO.

Smuts, J.C. [1926] 1987. Holism and Evolution. Cape Town: N\&S Press.

Sommers, Marc 2000. The Dynamics of Coordination, Thomas J. Watson Jr. Institute of International Affairs, Occasional Paper \#40, Providence.

Stedman, Stephen J. 1997. Spoiler Problems in Peace Processes. International Security 22 (2), $5-53$.

Stedman, S.J, Cousens, E. \& Rothchild, D. (eds) 2002. Ending Civil Wars: The Implementation of Peace Agreements. Boulder: Lynne Rienner.

Stockton, N. 2002. Strategic Coordination in Afghanistan. Kabul: Afghanistan Research and Evaluation Unit (AREU).

Suhrke, A. \& Samset, I. 2007. What's in a Figure? Estimating Recurrence of Civil War. International Peacekeeping 14 (2), 195-203.

United Nations Security Council. 2007. Special Research Report No. 2 of 2007, on the Peacebuilding Commission, 5 October 2007, New York: United Nations.

Uvin, P. 1999. The Influence of Aid in Situations of Violent Conflict: A Synthesis and Commentary on the Lessons Learned from Case Studies on the Limit and Scope of the Use of Development Assistance Incentives and Disincentives for Influencing Conflict Situations. DAC, Informal Task Force on Conflict, Peace and Development Cooperation, OECD, Paris.

Uvin, Peter 2002. The Development/Peacebuilding Nexus: A Typology and History of Changing Paradigms. Journal of Peacebuilding \& Development 1 (1).

Weir, E.A. 2006. Conflict and Compromise: UN Integrated Missions and the Humanitarian Imperative, KAIPTC Monograph No. 4, May 2006. 
